\title{
Integração de diferentes mídias digitais no ensino de Geometria: uma experiência com o oitavo ano do Ensino Fundamental
}

\author{
Eliane Teixeira Vargas - IM/PPGEMAT/UFRGS - eliane-vargas@hotmail.com \\ Márcia Rodrigues Notare - IM/PPGEMAT/UFRGS - marcia.notare@ufrgs.com
}

\begin{abstract}
Resumo
O presente artigo apresenta uma proposta de ensino de conceitos de Geometria integrando diferentes mídias digitais e recursos didáticos. O objetivo central do trabalho foi desenvolver uma proposta que integrasse diferentes mídias digitais no ensino de ângulos, retas paralelas, triângulos, soma dos ângulos internos, bissecção e trissecção de ângulos, além de disponibilizar um website composto por uma sequência didática envolvendo definições, resoluções de problemas, vídeos, glossário de termos e atividades a serem desenvolvidas com materiais manipulativos e com o software GeoGebra. Para analisar a proposta e o avanço dos alunos, utilizou-se como referenciais teóricos Vergnaud (1993) e Gravina (1996, 2001).
\end{abstract}

Palavras-chave: Geometria; mídias digitais; website; geometria dinâmica.

\section{Integration of different digital media in teaching geometry: an experience with the eighth grade of elementary school}

\begin{abstract}
This article presents a proposal for teaching the concepts of geometry by integrating different digital media and teaching resources. The central aim of the study was to develop a proposal that integrates different digital media in teaching angles, parallel lines, triangles, angle sum, bisection and trisection of angles, in addition to providing a website consists of a didactic sequence involving definitions, resolutions problems, videos, glossary of terms and activities to be undertaken with manipulative materials and the GeoGebra software . To analyze the proposal and the progress of the students, was used as theoretical frameworks Vergnaud (1993) and Gravina (1996, 2001).
\end{abstract}

Keywords: Geometry; digital media; website; dynamic geometry.

\section{Introdução}

O presente artigo discute e apresenta uma proposta de ensino que buscou integrar diferentes mídias digitais no ensino de alguns conceitos de Geometria, tais como ângulos, teoremas das retas paralelas e uma transversal, triângulos, soma dos ângulos internos, bissecção e trissecção de ângulos.

Para o desenvolvimento do trabalho, foi construído um website ${ }^{1}$ que apresenta um menu para cada conceito de Geometria abordado. Este website contém uma sequência didática envolvendo definições, resoluções de problemas, vídeos, glossário e atividades que podem ser desenvolvidas com materiais manipulativos e com o software GeoGebra.

Uma das ideias principais é que este material possa ser utilizado tanto como um recurso didático por professores de Matemática, quanto como uma fonte de pesquisa e de propostas de atividades para qualquer aluno que esteja interessado pelos conteúdos abordados no website.

A sequência de atividades foi aplicada com uma turma de alunos do oitavo ano do Ensino Fundamental de nove anos composta por vinte e cinco alunos e analisada à luz da teoria dos Campos Conceituais de Vergnaud (1993).

\section{Teoria dos Campos Conceituais}

\footnotetext{
${ }^{1}$ Disponível em: < http://profelianevargas.wix.com/ensinodeanguloeretas $>$.
} 
Discípulo de Piaget, Gérard Vergnaud, diretor de pesquisa do Centro Nacional de Pesquisa Científica (CNRS) da França, tem como foco em sua teoria o estudo do funcionamento cognitivo do -sujeito-em-situaçãoll. A Teoria dos Campos Conceituais é uma teoria cognitivista e tem como objetivo,

[...] propiciar uma estrutura às pesquisas sobre atividades cognitivas complexas, em especial com referência às aprendizagens científicas e técnicas. Trata-se de uma teoria psicológica do conceito, ou melhor, da conceitualização do real, que permite situar e estudar as filiações e rupturas entre conhecimentos, do ponto de vista de seu conteúdo conceitual. Ela também possibilita analisar a relação entre os conceitos enquanto conhecimentos explícitos e as invariantes operatórias implícitas nos comportamentos dos sujeitos em determinada situação, bem como aprofundar a análise das relações entre significados e significantes. Os exemplos foram colhidos em diversos campos conceituais: as estruturas aditivas, as estruturas multiplicativas, a lógica das classes, ou a álgebra. (Vergnaud, 1993, p. 1)

Segundo Vergnaud (2009, p.23), -Um conceito em ação é um conceito considerado pertinente na ação em situação. Um teorema em ação é uma proposição tida como verdadeira na ação em situaçãoll. Os conhecimentos contidos nos esquemas designam-se pelas expressões separadas -conceito-em-ação\| e -teorema-em-ação\|, ou pela expressão única -invariantes operatórias\|l. Podemos observar que, em situações de resolução de um problema, o sujeito constrói estruturas de esquemas, seja em sucesso ou fracasso, modificando o esquema inicial de acordo com a necessidade oriunda da resolução exata do problema proposto. Ainda,

Chamemos -esquemall a organização invariante do comportamento para uma classe de situações dada. É nos esquemas que se devem pesquisar os conhecimentos-em-ação do sujeito, isto é, os elementos cognitivos que fazem com que a ação do sujeito seja operatória. (Vergnaud, 1993, p. 2)

A Teoria dos Campos Conceituais pode ajudar a compreender a aprendizagem dos alunos quando são propostas atividades que utilizam mídias digitais, a partir do momento em que os mesmos estruturam esquemas para solucionar as atividades propostas de acordo com seus conhecimentos prévios e suas experiências e, caso tenham insucesso, é possível verificar os processos realizados, refletir e propor novas estratégias e tomadas de decisões, ou apenas utilizar algumas modificações nas estratégias antes estabelecidas.

Para Vergnaud (1993), no que se refere à aprendizagem de Matemática, existem vários esquemas e cada um se relaciona a uma classe de situações com características bem definidas. Porém, um sujeito pode aplicar um esquema de uma classe mais restrita e depois um esquema de uma classe mais ampla, denominado extensão do esquema. Este segundo permite generalização, transferência, deslocamento e descontextualização. Podemos tomar como exemplo, situações-problemas propostas aos alunos cuja resolução dá-se apenas com cálculos numéricos e, ao ampliar o problema para uma situação mais genérica, os alunos são levados a utilizarem procedimentos algébricos na resolução.

De acordo com Moreira (2002), Vergnaud define campo conceitual como um conjunto de situações (tarefas). A ideia é que toda a situação complexa pode ser resolvida por meio de uma junção de tarefas, cuja origem e dificuldades específicas devem ser bem conhecidas. 
Campo conceitual, para Vergnaud (1993), é um campo de estudo para dar significação às dificuldades percebidas na conceitualização do real, e, portanto a teoria dos campos conceituais presume que, para o desenvolvimento cognitivo de um sujeito, a conceitualização é essencial.

Na tentativa de compreender como os alunos aprendem Geometria, buscaramse referenciais teóricos que trouxessem experiências diversas sobre o desenvolvimento desta subárea da Matemática e que contribuíssem para o planejamento e para a aplicação da sequência didática desenvolvida neste trabalho.

\title{
2 As Mídias Digitais na Educação Matemática
}

Até a terça parte do XX, o uso de tecnologias não era habitual na rotina da população. No século XIX, o giz e o quadro-negro foram grandes legados para a Educação, o que se perdura até o século XXI. Gravina e Basso (2012) mostram que houve uma mudança na rotina das pessoas, de modo que diversas atividades rotineiras são resolvidas via tecnologias digitais, como por exemplo, para localizar um endereço, basta acessar um website de mapas por meio de aplicativos instalados em seus próprios celulares. Ainda, de acordo com Gravina e Basso (2012),

\begin{abstract}
Nossas rotinas de sala de aula também deveriam incorporar, cada vez mais, as tecnologias, pois elas também influem nas nossas formas de pensar, de aprender, de produzir. O -giz e quadro-negroll é uma tecnologia que teve seu momento de impacto no processo educativo, no século XIX. Com o crescimento das cidades decorrente da Revolução Industrial, a necessidade da educação em massa consolida a organização da sala de aula em grandes grupos com atenção voltada para a -falall do professor. [...]. (Gravina e Basso, 2012, p. 12)
\end{abstract}

Percebendo que essa tecnologia histórica continua sendo o principal recurso utilizado ainda nos dias de hoje nas salas de aula, e D’Ambrósio traz que a aula de matemática -[...] ainda é uma aula expositiva, em que o professor passa no quadro negro aquilo que ele julga importante. $\mathrm{O}$ aluno [...] copia da lousa para o caderno e em seguida procura fazer exercícios de aplicação [...].॥ (D’Ambrosio, 1989, p. 15), procurou-se inserir na prática docente o uso de recursos digitais, com o intuito de tornar as aulas mais atrativas e proporcionar aos alunos uma melhor compreensão dos conceitos matemáticos.

Gravina e Basso (2012) comentam sobre as possibilidades que a tecnologia digital proporciona nas aulas de Matemática, pois disponibilizam ferramentas interativas que criam objetos dinâmicos e manipuláveis, auxiliando o processo de aprendizagem e o desenvolvimento cognitivo dos educandos.

Desta forma, percebe-se a importância do uso de tecnologias de informação e comunicação nas propostas para ensino de geometria. De acordo os Parâmetros Curriculares Nacionais,

O computador pode ser usado como elemento de apoio para o ensino [...], mas também como ferramenta para o desenvolvimento de habilidades. O trabalho com o computador pode ensinar o aluno a aprender com seus erros e a aprender junto com seus colegas, trocando produções e comparando-as. (Brasil, 1997, p. 48).

Com a utilização dos recursos tecnológicos, em especial os programas de geometria dinâmica, a aprendizagem dos alunos quanto aos conceitos matemáticos pode ser muito mais expressiva, visto que partem de um processo estático que os livros e 
quadro-negro trazem, para um processo de construção de conceitos, conjecturas, argumentação e demonstração através dos desenhos em movimento. Gravina (1996) aponta dois aspectos didáticos importantes para o uso dos programas de geometria dinâmica,

Dois são os principais aspectos didáticos para utilização dos programas: a) os alunos constroem os desenhos de objetos ou configurações, quando o objetivo é o domínio determinados conceitos através da construção; b) recebem desenhos prontos, projetados pelo professor, sendo o objetivo a descoberta de invariantes através da experimentação e, dependendo do nível da escolaridade dos alunos, num segundo momento, trabalham as demonstrações dos resultados obtidos experimentalmente. (Gravina, 1996, p. 7).

Pesquisas mostram que os ambientes dinâmicos já se revelam como ferramentas promissoras no quesito superação de dificuldades inerentes à geometria, visto que os alunos se sentem mais motivados a procurar esclarecimentos para conjeturas surgidas em função da manipulação dos objetos geométricos dinâmicos (Gravina, 2001).

\section{Desenvolvimento da proposta de ensino}

O plano de ensino elaborado para esta pesquisa buscou integrar diferentes mídias digitais no ensino de alguns conceitos de Geometria, tais como ângulos, teoremas das retas paralelas e uma transversal, triângulos, soma dos ângulos internos, bissecção e trissecção de ângulos. As atividades foram pensadas para alunos do oitavo ano do Ensino Fundamental de nove anos, e aplicadas em uma turma composta por vinte e cinco alunos, no nível fundamental, na escola C.M.E.B. Maria Lygia Andrade Haack, da rede municipal de Esteio/RS.

O plano de ensino tem como focos principais as ações abaixo relacionadas.

$>\quad$ Propor situações e construções no GeoGebra para que através destas os alunos definam os elementos primitivos da geometria (ponto, retas e plano), assim como, conheçam o software e aprendam a manuseá-lo;

$>\quad$ Através de vídeos sensibilizadores reconhecer que os ângulos estão presente no cotidiano, propondo atividades que envolvam fotografias e construções dinâmicas no GeoGebra;

> Construir o conceito e as propriedades do Teorema de duas retas paralelas e uma transversal por meio de uma situação-problema, após

realizar a construção de um objeto em movimento no GeoGebra;
Através de construções e atividades propostas diretamente no website, classificar triângulos quanto aos lados e ângulos internos, assim como, verificar a soma dos ângulos internos;

Resgatar o problema da trissecção, e construir um instrumento trissector utilizando materiais concretos e outro utilizando o software GeoGebra para perceber a facilidade que a geometria dinâmica proporciona;

\subsection{Apresentação do website}

O website criado para essa sequência didática foi intitulado como Ensino e Aprendizagem de Ângulos e Retas, e está disponível no endereço eletrônico http://profelianevargas.wix.com/ensinodeanguloeretas. O mesmo é composto por oito menus (Home, Retas, Ângulos, Retas paralelas e uma transversal, Triângulos, Trissecção de um ângulo, Links e Sobre a autora). Em cada menu, buscou-se contemplar os objetivos de conceituar e verificar as propriedades dos conteúdos mencionados acima, através da integração de diferentes mídias digitais propondo 
atividades que envolvessem animações e objetos manipuláveis, tanto online no website como construções dinâmicas do software GeoGebra. A Figura 1 abaixo é a homepage da website.

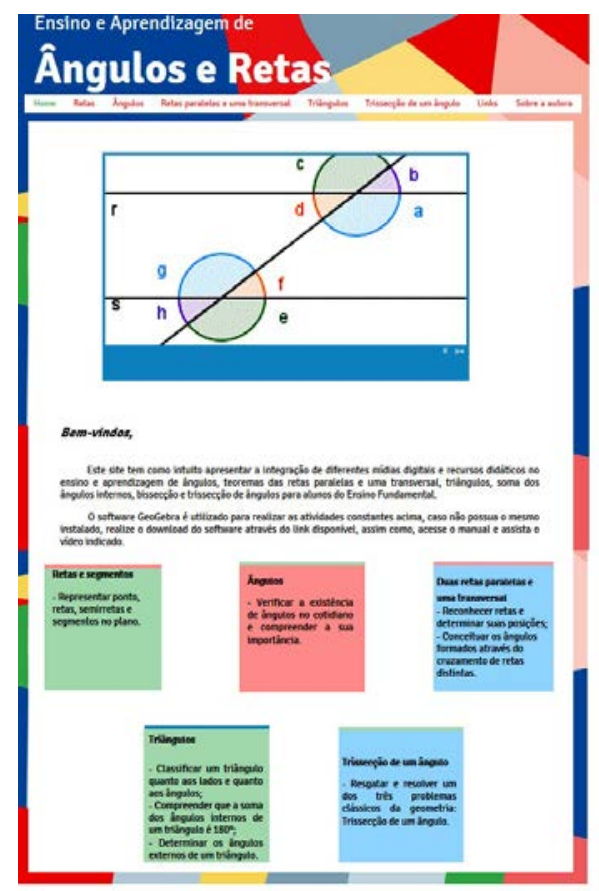

Figura 1 - Homepage

\section{A experiência didática e sua análise}

O plano de ensino apresentado no capítulo anterior foi desenvolvido na integra no oitavo ano do Ensino Fundamental, numa turma composta por 25 alunos, no nível fundamental, da escola C.M.E.B. Maria Lygia Andrade Haack, da rede municipal de Esteio/RS. A seguir, serão apresentadas análises de duas atividades desenvolvidas com os alunos.

\subsection{Construção do leque}

Uma das atividades propostas aos alunos foi a construção de uma figura dinâmica, no GeoGebra, referente aos objetos apresentados em um dos vídeos assistidos previamente no terceiro menu, que abordava o conceito de ângulo: tesoura ou leque. Estes dois objetos, de fato, representam modelos reais e dinâmicos nos quais o conceito de ângulo está presente. Inicialmente, foram explorados os objetos disponíveis no website e a turma teve a opção de livre escolha para sua construção. A turma optou por fazer a construção do leque, que deveria apresentar movimento dinâmico de abrir e fechar sem deformar, ou seja, preservando as propriedades geométricas pertinentes para sua construção.

Foram surpreendentes os resultados atingidos pelos alunos. Os mesmos tentaram deixar seus trabalhos o mais parecido possível com o objeto do vídeo. Utilizaram pontos móveis sobre o arco e construíram os lados com segmentos, sem solicitar ajuda da professora, ilustrado pelas Figuras 2 e 3 abaixo. 


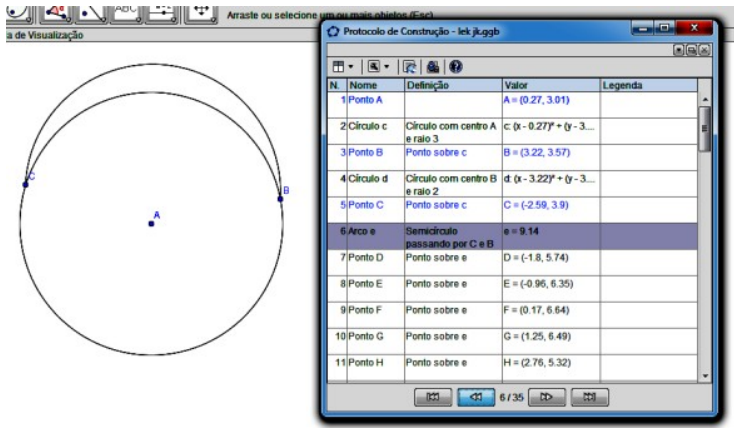

Figura 2 - Leque: início construção

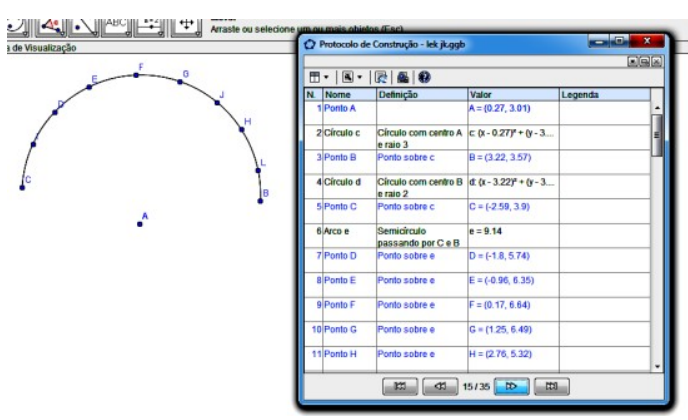

Figura 3 - Leque: marcação das hastes

A Figura 2 mostra o início de uma construção, no qual foi feito um círculo de centro no ponto A e raio 3, com a ferramenta Círculo dados Centro e Raio. Em seguida, foi traçado um semicírculo, cujos pontos dos extremos pertencem à circunferência do círculo inicial. Para a continuação da construção, o objeto inicial foi ocultado, ferramenta útil e interessante que a geometria dinâmica possibilita. A utilização da circunferência inicial de raio fixo é para o tamanho do leque não modificar ao ser produzido o movimento de abrir e fechar. Porém, como algumas duplas de alunos realizaram essa construção utilizando a ferramenta semicírculo, o efeito do movimento produzido foi diferente, pois a ferramenta mais adequada para essa construção seria Arco Circular dados Centro e dois Pontos, para que o movimento ocorresse sobre a circunferência de acordo com o exemplo apresentado.

Na Figura 3 foram distribuídos pontos aleatórios sobre o semicírculo, podendo ser observado que o ângulo foi dividido em partes diferentes, depois foram traçados os segmentos que formam as hastes que ligam o extremo superior ao extremo inferior de onde surgem os movimentos articulados do leque. No decorrer da aula, pode-se observar que os alunos tinham a preocupação em distribuir os pontos de modo que as pás tivessem mesmas medidas, porém faltou mais intimidade e domínio do software, por isso não souberam utilizar as ferramentas adequadas. Posteriormente, ao acompanhar a construção feita pela professora, os mesmos tomaram conhecimento da forma correta de como dividir o ângulo deixando as pás do leque com medidas iguais.

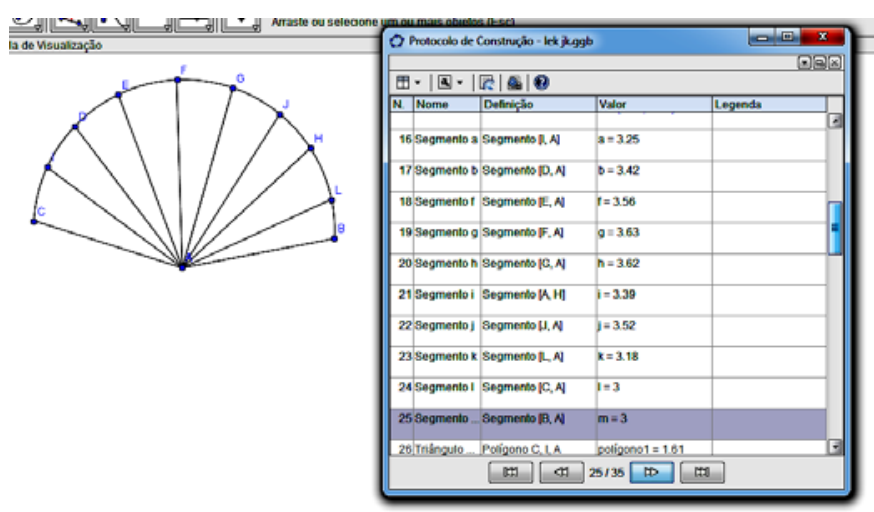

Figura 4 - Leque: hastes

Na Figura 4, o leque já está com o processo de construção avançado, faltando apenas colorir cada aba.

De um modo geral, os trabalhos foram classificados como válidos, visto o envolvimento e aprendizagem que proporcionaram aos alunos. No final das construções 
apresentadas, os alunos perceberam que houveram pequenos problemas na construção de seus objetos, como por exemplo, o movimento de abrir e fechar na realidade aumentava e diminuía o tamanho do leque, assim solicitaram explicações individuais sobre o qual erro cometido na construção e qual seria a forma correta. Estas construções possibilitaram aos alunos visualizar que o movimento de abrir e fechar do leque forma ângulos de medidas diferentes, ou seja, dependendo de sua abertura, sua classificação muda, conforme ilustra a Figura 5.

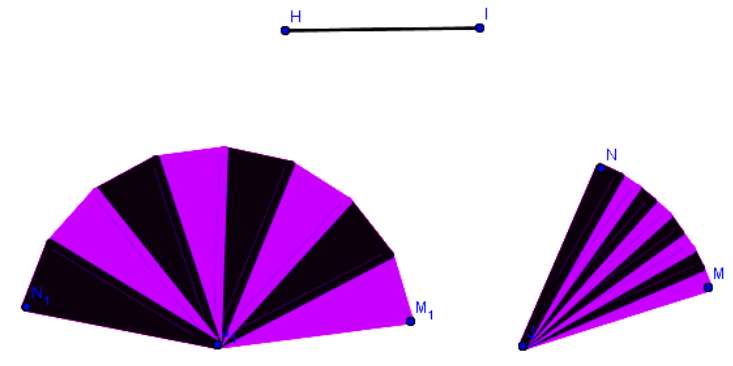

Figura 5 - Leque

Os alunos, para construírem o leque, necessitaram utilizar tanto o conhecimento visto na aula (ângulos no cotidiano) quanto os conhecimentos básicos vistos anteriormente (circunferência, pontos, segmentos e retas). Assim ao desenvolveram a atividade proposta os alunos além de reconhecer e a aplicar esses conceitos, puderam observar que os mesmos estão presentes nos objetos reais do nosso cotidiano.

Para Vergnaud (1983b, p. 127) citado por Moreira (2002, p. 3), -Campo conceitual é também definido por Vergnaud como um conjunto de problemas e situações cujo tratamento requer conceitos, procedimentos e representações de tipos diferentes, mas intimamente relacionados.\|.

A geometria dinâmica teve participação direta para que os alunos concluíssem essa atividade com êxito, pois através do -objeto em movimento\| os leques atingiram o efeito desejado. O GeoGebra permitiu que os alunos utilizassem seus esquemas de acordo com seus conhecimentos prévios, e a partir das construções e manipulações, estes esquemas iniciais foram se ampliando, agregando novas estratégias e novas opções de ferramentas utilizadas. Para Vergnaud (1993), nem sempre os esquemas têm resultados satisfatórios, eles podem ter sucesso ou fracasso, por isso a construção dos leques no GeoGebra foi válido, pois os alunos conseguiram observar que algo estava incoerente e, a partir de novas exemplificações de ferramentas que o software oferece, os esquemas puderam ser novamente organizados, obtendo resoluções diferentes.

O GeoGebra, por oferecer em suas ferramentas os mesmos instrumentos manipulativos (régua e compasso), permiti que seja realizadas atividades que envolvem resoluções concretas e virtuais, para oportunizar aos alunos a manipulação destas ferramentas em ambos ambientes. Para Gravina et al. (2012, p.38) softwares de geometria dinâmica, $-[$...]. São ambientes que concretizam a geometria euclidiana plana, e diferente daquilo que obtemos com lápis e papel e régua e compasso, pois com o mouse podemos manipular as figuras que estão na tela do computador, ao aplicar movimento em pontos que estão na construção.॥.

\subsection{Construção da escada}

Outra atividade interessante constante no website abordou uma situaçãoproblema envolvendo os degraus de uma escada e os ângulos formados entre essa e uma reta transversal sob seus degraus, sendo necessária para sua resolução a aplicação do 
teorema de duas retas paralelas e uma transversal. Além disso, a mesma também envolveu a abordagem dos conceitos de retas paralelas e perpendiculares. No quadro, inicialmente a professora desenhou a simulação da situação-problema, ou seja, a escada e a reta transversal sob seus degraus, iniciando então os questionamentos referentes à posição dos degraus quanto à formação de retas paralelas e perpendiculares, assim como, ao traçar uma reta transversal, observar os ângulos formados.

A partir da participação dos alunos, foram conceituados os ângulos formados entre duas retas paralelas e uma transversal, reconhecendo que existem, nesta configuração de retas, ângulos correspondentes, ângulos alternos e ângulos colaterais. Após esta discussão, utilizamos a escada dinâmica, disponível no website, para movimentar e explorar diferentes posições, fazendo surgir regularidades que esclarecem angulosos conceitos estudados.

A tarefa proposta para o GeoGebra foi a construção de uma escada que não deformasse sob a ação do movimento, ou seja, que preservasse as propriedades utilizadas na construção, garantindo congruências, paralelismos e perpendicularismos. Nesse primeiro momento, não foram fornecidas dicas para a construção da escada. Os alunos tiveram a oportunidade de explorar e manipular o exemplo disponível no website, para identificar suas regularidades e utilizá-las em suas construções. As construções foram bem variadas, porém nenhuma apresentou o movimento sem deformação, conforme o solicitado.

Em um segundo momento, a professora solicitou que os alunos acompanhassem o protocolo da construção da escada disponível no website, observando as propriedades que foram utilizadas na construção, para que percebessem qual 0 problema ou irregularidades de suas construções. Em seguida, foi solicitada a construção de uma segunda escada, utilizando as propriedades observadas. Os alunos acompanharam algumas dicas iniciais, que alertavam sobre a importância em utilizar retas paralelas, retas perpendiculares e a ferramenta compasso para garantir a congruência dos degraus, e assim finalizaram suas construções. Nesta atividade, ocorreram diversas situações: uma delas, ilustrada na Figura 6, contemplou a atividade, pois não se deforma sob a ação do movimento, evidenciando que o aluno identificou, a partir da exploração e da intervenção da professora, as propriedades necessárias para garantir a construção de uma escada com degraus de mesmo tamanho e perpendiculares entre si.

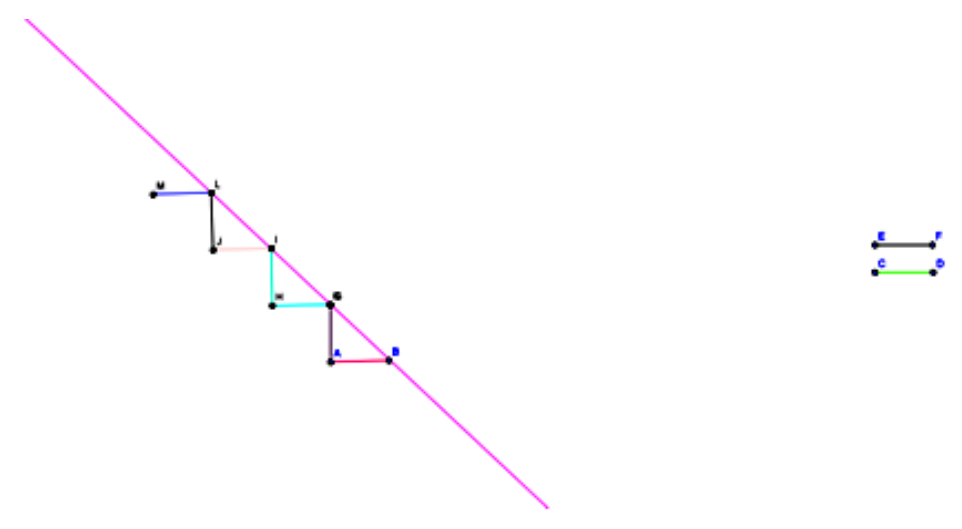

Figura 6 - Escada com movimento dos alunos D. e Y.

Podemos observar que a professora iniciou o tópico tentando dar sentido a uma situação real, o que segundo Vergnaud (1993) é a essência do campo conceitual. Para Moreira (2002), 
Vergnaud considera o campo conceitual como uma unidade de estudo para dar sentido às dificuldades observadas na conceitualização do real e, como foi dito antes, a teoria dos campos conceituais supõe que a conceitualização é a essência do desenvolvimento cognitivo. (Moreira, 2002, p. 3).

O desenho também é uma forma de linguagem e expressão e isso facilita a compreensão dos alunos para chegar a determinados conceitos. A partir desta proposta, os alunos construíram esquemas para a resolução da situação sugerida e o GeoGebra deu o suporte necessário para esse trabalho. Como Gravina (2001) afirma, o -desenho em movimentoll revela as invariantes implícitas, permitindo a percepção dos alunos quanto aos esquemas utilizados, percebendo seus erros de construção e consentindo uma retomada de decisões. A geometria dinâmica proporciona também uma significação ao imaginário construído através de uma situação-problema, estimulando o raciocínio, habilidade e concretizando o objeto construído no mental em objeto concreto manipulável, e ainda

[...]. Raciocinar sobre determinado problema significaria construir e manipular modelos mentais da situação sob exame, tendo-se como suporte a tecnologia informática; compreender uma teoria significaria a interiorização de modelos já construídos; e comunicar significaria estabelecer sintonia entre modelos mentais, passíveis de serem concretizados. (Gravina, 2001, p. 38).

A geometria dinâmica contribuiu como uma ferramenta para provocar desafios e incitar o pensamento geométrico dos alunos, nas quais as tarefas propostas estimularam a compreensão textual, habilidade e aplicação de conceitos e propriedades, além disso, os alunos puderam ter a experiência de realizar no ambiente virtual, atividades que na maioria das vezes são vistas apenas no concreto utilizando quadronegro, giz e réguas.

Em ambas as experiências didáticas, construções do leque e da escada, se fizeram presente os conceitos dos campos conceituais de Vergnaud, tendo em vista que os alunos necessitaram elaborar esquemas para resolver as situações propostas (conceito-em-ação) para construir e obter o conceito almejado, sempre resgatando e aplicando conceitos anteriormente estudados.

\section{Considerações Finais}

Através dessa prática a autora percebeu que através da integração de diferentes mídias digitais e recursos didáticos, é possível proporcionaram aos alunos do Ensino Fundamental, ensino e aprendizagem de conceitos geométricos antes vistos e explorados pela mesma em sua prática docente apenas com materiais concretos.

Com este trabalho, percebemos que a geometria dinâmica, juntamente com a organização dos demais recursos didáticos, possibilitou que os alunos explorassem e vivenciassem situações com os conceitos geométricos abordados, assim como, tivessem a oportunidade de compreender e aplicar diferentes propriedades destes conceitos.

Nessa sequência didática se visou propriciar um estudo, envolvendo situações que adquirissem sentido ao educando, e que ao mesmo tempo resgatassem a cada tópico conceitos e propriedades vistas anteriormente a fim de utilizá-los em uma nova situação para dar sentido a esse, contemplando a teoria dos campos conceituais. 
Os principais aspectos observados nos alunos foram comprometimento, empenho e o entusiasmo durante a realização do trabalho. Mais do que isso, percebeu-se a forma positiva com que demonstraram os conhecimentos adquiridos, realizando as atividades propostas através dos conceitos geométricos construídos.

Os resultados obtidos tanto nas duas atividades apresentadas (construção do leque e construção da escada), quanto na exploração do material manipulativo disponível no website construído para esse trabalho, foram satisfatórios, pois despertaram o interesse dos alunos em manusear e realizar as tarefas propostas, e através dos diálogos, questionamentos e manipulações os mesmos construíram os conceitos almejados para essas propostas (ângulos no cotidiano e o teorema das retas paralelas e uma transversal).

Desse modo acredita-se que esse trabalho possa servir de referencia ou auxiliar a outros educadores na abordagem desses conceitos de Geometria para alunos do Ensino Fundamental.

\section{Referências}

BRASIL. Parâmetros Curriculares Nacionais: Matemática. 2a ed. Brasília, 1997. D’AMBrosio, B. Como ensinar matemática hoje. Temas \& Debates. Sociedade Brasileira de Educação Matemática. Ano II, Nº 2. Brasília, 1989. p.15-19.

GRAVINA, M. A. Geometria Dinâmica: uma nova abordagem para o aprendizado da geometria. Anais do VII Simpósio Brasileiro de Informática na Educação. Belo Horizonte, Brasil, Nov. 1996. p. 1-13. Disponível em: < http://www.educadores.diaadia.pr.gov.br/arquivos/File/2010/artigos_teses/EDUCACA O_E_TECNOLOGIA/GEODINAMICA.PDF > . Acesso em: 22 fev. 2014.

—. Os ambientes de geometria dinâmica e o pensamento hipotético-dedutivo. Rio Grande do Sul: UFRGS, 2001. 277 p. Tese de Doutorado. Disponível em: < http://www.lume.ufrgs.br/handle/10183/2545>. Acesso em: 23 set. 2013.

GRAVINA, M. A., e M. V. A. BASSO. Mídias digitais na Educação Matemática. In: GRAVINA, M. A.; BÚRIGO, E. Z.; BASSO, M. V. A.; GARCIA, V. C. V. (Orgs). In: Matemática, Mídias Digitais e Didática: tripé para formação do professor de Matemática. Porto Alegre: Evangraf, 2012. p. 11 - 35.

GRAVINA, M. A., M. M. BARRETO, M. T. DIAS, e M. MEIER. Geometria Dinâmica na Escola. In: GRAVINA, M. A.; BÚRIGO, E. Z.; BASSO, M. V. A.; GARCIA, V. C. V. (Orgs). In: Matemática, Mídias Digitais e Didática: tripé para formação do professor de Matemática. Porto Alegre: Evangraf, 2012. p. 37-60.

MOREIRA, Marco Antônio. A Teoria dos Campos Conceituais de Vergnaud, o ensino de ciências e a pesquisa nesta área. UFRGS. 2002. Disponível em: $<$ http://www.if.ufrgs.br/public/ensino/vol7/n1/v7_n1_a1.html $>$. Acesso em: 29 set. 2013.

VERGNAUD, Gérard. O que é aprender? In: BITTAR, Marilena; MUNIZ, Cristiane Alberto (Orgs). In: A aprendizagem matemática na perspectiva da Teoria dos Campos Conceituais. Curitiba: CRV, 2009. p. 13-36.

VERGNAUD, Gérard. In: Nasser, L. (ED.). Teoria dos Campos Conceituais. $1^{\circ}$ Seminário Internacional de Educação Matemática do Rio de Janeiro. Anais. Rio de Janeiro, 1993. p. 1-26. 